\title{
PENERAPAN ANALISIS CLUSTER DENGAN METODE HIERARKI UNTUK KLASIFIKASI KABUPATEN/KOTA DI PROVINSI MALUKU BERDASARKAN INDIKATOR INDEKS PEMBANGUNAN MANUSIA
}

\author{
M. Y. Matdoan ${ }^{1 *}$, M. S. Noya Van Delsen²) \\ 1*Program Studi Statistika, FMIPA Universitas Pattimura \\ Email: yahya.matdoan@fmipa.unpatti.ac.id \\ ${ }^{2}$ Program Studi Statistika, FMIPA Universitas Pattimura \\ Email: marlonnvd@gmail.com
}

\begin{abstract}
Human Development Index is an indicator used to measure one important aspect related to the quality of the results of economic development, namely the degree of human development. HDI in Maluku Province from year to year always increases. But always below the national rate. This is due to development that was not carried out evenly and not on target. Cluster analysis is a multivariate method that has a purpose for grouping, where a group has relatively similar characteristics (homogeneous), while between groups have different characteristics. This research shows that the best method in the analysis of cluster hierarchies is the ward's method. Therefore, 4 clusters were obtained in HDI in Maluku Province which included HDI with a high category, namely Kota Ambon, continued HDI with a medium category, namely Maluku Tengah Regency, then HDI with a low category, namely Maluku Tenggara, Buru, Kepulauan Aru, Seram Bagian Barat and Kota Tual, Continuing HDI with very low categories, Kepulauan Tanimbar Regency, Seram Bagian Timur, Maluku Barat Daya and Buru Selatan Regency.
\end{abstract}

Keywords: Human Development Index, Cluster, Hierarchy

ABSTRAK

IPM merupakan indikator yang digunakan untuk mengukur salah satu aspek penting yang berkaitan dengan kualitas dari hasil pembangunan ekonomi, yakni derajat perkembangan manusia. IPM di Provinsi Maluku dari tahun ke tahun selalu mengalami peningkatan. Namun selalu di berada di bawah angka nasional. Hal ini disebabkan karena pembangunan yang tidak terlaksana secara merata dan tidak tepat sasaran. Analisis cluster merupakan metode multivariat yang mempunyai tujuan untuk pengelompokkan, dimana suatu kelompok mempunyai ciri yang relatif sama (homogen), sedangkan antar kelompok memiliki ciri yang berbeda. Penelitian ini diperoleh hasil bahwa metode terbaik dalam analsisis cluster hierarki adalah metode ward's. Oleh Karena itu, diperoleh 4 cluster pada IPM di Provinsi Maluku yang meliputi IPM dengan kategori tinggi yaitu Kota Ambon, selanjunya IPM dengan kategori sedang yaitu Kabupaten Maluku Tengah, selanjutnya IPM dengan kategori rendah yaitu Kabupaten Maluku Tenggara, Buru, Kepulauan Aru, Seram Bagian Barat dan Kota Tual, Selanjunya IPM dengan kategori sangat rendah yaitu Kabupaten Kepulauan Tanimbar, Seram Bagian Timur, Maluku Barat Daya dan Kabupaten Buru Selatan.

Kata kunci: Indeks Pembangunan Manusia, Cluster, Hierarki 


\section{PENDAHULUAN}

Pencapaian pembangunan ekonomi suatu wilayah dipengaruhi oleh proses pembangunan manusia. Pencapaian tersebut tidak terlepas dari seberapa besar kualitas manusia di suatu wilayah. Indikator yang bisa mengukur kualitas manusia disuatu daerah yaitu dengan Indeks Pembangunan Manusia (IPM). IPM merupakan indikator yang digunakan untuk mengukur salah satu aspek penting yang berkaitan dengan kualitas dari hasil pembangunan ekonomi, yakni derajat perkembangan manusia. IPM mempunyai tiga unsur yaitu kesehatan, pendidikan yang dicapai, dan standar kehidupan atau sering disebut ekonomi. Jadi ketiga unsur ini sangat penting dalam menentukan tingkat kemampuan suatu provinsi untuk meningkatkan IPMnya. Ketiga unsur tersebut tidak berdiri sendiri, melainkan saling memengaruhi satu sama yang lainya (Tangga $R$ et.al 2013). Selain itu juga dipengaruhi oleh faktor-faktor lain, seperti ketersediaan kesempatan kerja, pertumbuhan ekonomi, infrastruktur dan kebijakan pemerintah. Jadi IPM di suatu daerah akan meningkat apabila ketiga unsur tersebut dapat ditingkatkan. Nilai IPM yang tinggi menandakan keberhasilan pembangunan ekonomi di daerah tersebut (Tambunan, 2003).

Provinsi Maluku merupakan provinsi yang berbatasan dengan laut seram di bagian utara, samudra hindia dan laut arafuru di bagian selatan, papua di bagian timur dan sulawesi di bagian barat. IPM di Provinsi Maluku pada tahun 2016 sebesar 67,60 kemudian pada tahun 2017 sebesar 68,19, kemudian pada tahun 2018 sebesar 68,87 dan pada tahun 2019 sebesar 69,45. Hal ini dapat dikatakan bahwa IPM di Provinsi Maluku dari tahun ke tahun selalu mengalami peningkatan (BPS Maluku, 2019). Namun selalu di berada di bawah angka nasional. Hal ini disebabkan karena pembangunan yang dilakukan oleh pemerintah tidak terlaksana secara merata atau dengan kata lain pemerintah dalam melaksanakan pembangunan di daerah tidak tepat sasaran. Maka dari itu, salah satu solusi yang bisa diterapkan adalah mengelompokan Kabupaten/Kota berdasarkan indikator IPM, sehingga pemerintah dapat mengambil atau memutuskan kebijakan dan strategi yang baik dan tepat sasaran dalam pembangunan (Matdoan, 2019).

Analisis cluster merupakan metode multivariat yang mempunyai tujuan untuk untuk pengelompokkan, dimana suatu kelompok mempunyai ciri yang relatif sama (homogen), sedangkan antar kelompok memiliki ciri yang berbeda. Pada umumnya suatu objek dimasukkan ke dalam suatu klaster atau kelompok sehingga lebih cenderung berhubungan (berkorelasi) dengan objek lainnya di dalam klastermya daripada dengan objek dari klaster lain. Pembentukan klaster didasarkan pada kuat tidaknya hubungan antar objek (Lina, 2011).

Secara umum terdapat dua metode pengelompokan data dalam analisis cluster yaitu metode hierarki dan metode non-hierarki (Rita, 2016). Analisis cluster hierarki memiliki beberapa metode yaitu metode Pautan Tunggal (Single Linkage), metode Pautan lengkap (Complete Lingkage), metode Antar Pusat (Centroid Lingkage), metode pautan Rata-rata (Average Lingkage) dan metode Ward (Ward's Method) (Fathia AN et.al, 2016). Dalam penilitian ini akan mengklasifikasi Kabupaten/Kota di Provinsi Maluku berdasarkan indikator Indeks Pembangunan Manusia (IPM).

\section{METODE PENELITIAN}

\subsection{Sumber Data}

Data yang digunakan dalam penelitian ini adalah data sekunder yang diperoleh dari Badan Pusat Statistik (BPS) Provinsi Maluku tahun 2018. 


\subsection{Variabel Penelitian}

Dalam penelitian ini data diklasifikasikan menurut 11 Kabupaten dan Kota di Provinsi Maluku.

Tabel 1 Variabel Peneltian

\begin{tabular}{cl}
\hline Variabel & \multicolumn{1}{c}{ Keterangan } \\
\hline $\mathrm{X}_{1}$ & Presentase Penduduk Miskin \\
$\mathrm{X}_{2}$ & Jumlah Sarana Kesehatan \\
$\mathrm{X}_{3}$ & Presentase Penduduk yang berpendidikan di atas SLTP \\
$\mathrm{X}_{4}$ & PDRB perkapita \\
$\mathrm{X}_{5}$ & Presentase Penduduk yang Memilki Keluhan Kesehatan \\
$\mathrm{X}_{6}$ & Tingkat Partisipasi Angkatan Kerja \\
$\mathrm{X}_{7}$ & Angka Beban Ketergantungan Penduduk \\
\hline
\end{tabular}

\subsection{Teknik Analisis Data}

Pada penelitian ini digunakan analisis klaster hierarki dengan metode Single Linkage, Average Linkage, Complete Linkage, Ward's, dan Centroid. Pengolahan data dalam penelitian ini menggunakan software IBM SPSS 22. Langkah-langkah analisis data yang digunakan adalah sebagai berikut.

1. Mengumpulkan data.

2. Menghitung statistik deskriptif berdasarkan variabel penelitian.

3. Melakukan pengujian asumsi analisis klaster

a. Sampel harus mewakili populasi

Pengujian ini dilakukan dengan menggunakan nilai Kaiser-Mayer-Olkin (KMO).

b. Multikolinieritas

Untuk mengetahui apakah data terindikasi kasus multikolinieritas dilakukan dengan melihat nilai Tollerance dan Varians Inflation Factor (VIF)..

4. Memilih prosedur analisis klaster Pada penelitian ini digunakan analisis klaster hierarki dengan menggunakan metode Single Linkage, Average Linkage, Complete Linkage, Ward's, dan Centroid.

5. Menentukan banyaknya klaster

6. Melakukan interpretasi hasil analisis

Setelah didapatkan hasil analisis klaster, maka tahap selanjutnya adalah menjelaskan mengenai klaster yang terbentuk.

\section{HASIL DAN PEMBAHASAN}

\subsection{Gambaran Umum IPM di Provinsi Maluku}

Analisis Deskriptif berdasarkan Indeks Pembangunan Manusia (IPM) Kabupaten/Kota di Provinsi Maluku tahun 2018. 


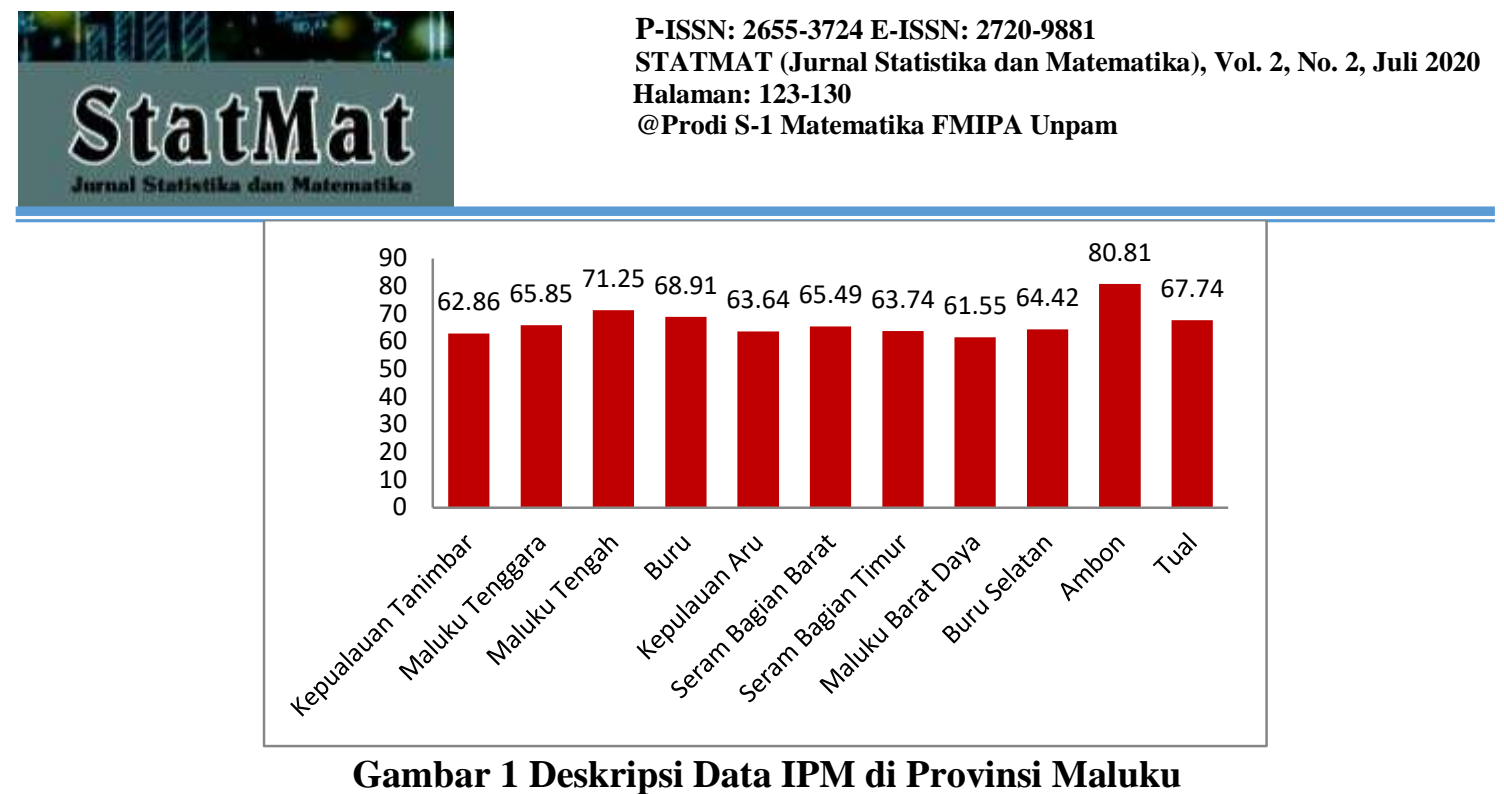

Berdasarkan Gambar 1, dapat dilihat bahwa IPM tertinggi di Provinsi Maluku yaitu di Kota Ambon dengan IPM sebesar 80,81 selanjutnya Kabupaten Maluku Tengah dengan IPM sebesar 71,25 dan IPM terendah yaitu Kabupaten Maluku Barat Daya (MBD) dengan IPM sebesar 61,55. Selanjutnya Statistik deskriptif Indikator Indeks Pembangungan Manusia (IPM) Kabupaten/Kota di Provinsi Maluku dapat dilihat pada Tabel 2.

Tabel 2. Statistik Deskriptif Indikator Indeks Pembangunan Manusia IPM

\begin{tabular}{rrrr} 
& N & Minimum & Maximum \\
\hline X1 & 11 & 4,57 & 29,43 \\
X2 & 11 & 15,00 & 47,00 \\
X3 & 11 & 12,76 & 35,52 \\
X4 & 11 & 2,86 & 33,31 \\
X5 & 11 & 16,08 & 24,82 \\
X6 & 11 & 57,10 & 74,45 \\
X7 & 11 & 46,77 & 75,78 \\
\hline
\end{tabular}

Berdasarkan Tabel 2, dapat dilihat bahwa variabel $\mathrm{X}_{1}$ memperoleh nilai minimum sebesar 4,57, nilai maksimum sebesar 29,43, selanjutnya variabel $\mathrm{X}_{2}$ memperoleh nilai minimum sebesar 15 dan nilai maksimum sebesar 47 , selanjunya variabel $\mathrm{X}_{3}$ memperoleh nilai minimum sebesar 12,76 dan nilai maksimum sebesar 35,52 selanjunya variabel $\mathrm{X}_{4}$ memperoleh nilai minimum sebesar 2,86 dan nilai maksimum sebesar 33,31, selanjunya variabel $\mathrm{X}_{5}$ memperoleh nilai minimum sebesar 16,08 dan nilai maksimum sebesar 24,82, selanjunya variabel $\mathrm{X}_{6}$ memperoleh nilai minimum sebesar 57,10 dan nilai maksimum sebesar 74,45 , selanjunya variabel $\mathrm{X}_{7}$ memperoleh nilai minimum sebesar 46,77 dan nilai maksimum sebesar 75,78.

\subsection{Asumsi Analisis Klaster}

\subsubsection{Asumsi Sampel yang Mewakili}

Hasil dari Pengujian Asumsi dengan Kaiser-Meyer-Olkin Measure (KMO) sebagai berikut. 
Tabel 3 Uji KMO and Bartlett's Test

Kaiser-Meyer-Olkin Measure of Sampling Adequacy.

.681

\begin{tabular}{llr}
\hline Bartlett's Test of Sphericity & Approx. Chi-Square & 56.738 \\
& Df & 21 \\
& Sig. & .000 \\
\hline
\end{tabular}

Berdasarkan Tabel 3, Diperoleh nilai Kaiser-Meyer-Olkin Measure of Sampling Adequacy yaitu sebesar 0,681. Nilai KMO sebesar 0,681 berkisar antara 0,5 sampai 1, maka dapat disimpulkan bahwa sampel dapat mewakili populasi dan variabel-variabel dapat dipakai untuk dianalisis lebih lanjut.

\subsubsection{Asumsi Multikolinieritas}

Untuk mendeteksi adanya multikolinieritas, dapat dilakukan dengan menggunakan nilai Tolerance (Tol) atau Variance Inflation Factor (VIF) untuk setiap variabel prediktornya.

Tabel 4 Uji Multikolinieritas

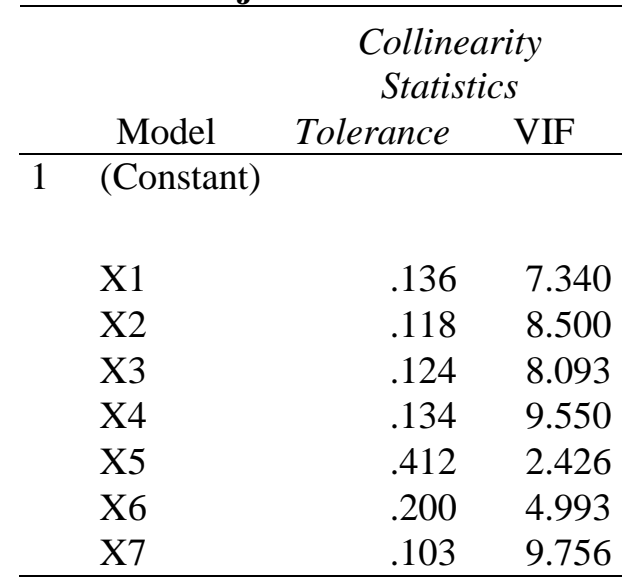

Berdasarkan Tabel 4, dapat dilihat bahwa nilai Tolerance dari Variabel $\mathrm{X}_{1}, \mathrm{X}_{2}, \mathrm{X}_{3}$, $\mathrm{X}_{4}, \mathrm{X}_{5}, \mathrm{X}_{6}$ dan $\mathrm{X}_{7}$ Lebih besar dari 0,10. Sementara itu, Nilai VIF dari Variabel $\mathrm{X}_{1}, \mathrm{X}_{2}, \mathrm{X}_{3}$, $\mathrm{X}_{4}, \mathrm{X}_{5}, \mathrm{X}_{6}$ dan $\mathrm{X}_{7}$ Lebih kecil dari 10. Oleh karena itu, dapat disimpulkan bahwa tidak terdapat indikasi masalah multikolineriatas pada variabel prediktor.

\subsection{Analisis Klaster denga Metode Hierarki}

Pada penelitian ini analisis cluster yang digunakan yaitu dengan metode hierarki yang meliputi Single Linkage, Average Linkage, Complete Linkage, Ward's, dan Centroid. Proses pengelompokan dengan menggunakan 5 metode ini akan diperoleh satu metode terbaik untuk menentukan komposisi kelompok dengan melihat nilai indeks RMSSTD (Root Mean Square Standart Deviation) terkecil sebagai penentuan jumlah kelompok yang dipilih. Ukuran jarak yang digunakan pada analisis kelompok tentang tingkat kesehatan di kabupaten/kota adalah jarak Mahalanobis. Nilai indeks RMSSTD pada setiap metode di atas dapat dilihat nilai indeks RMSSTD minimum dari keseluruhan pada Tabel 5. 


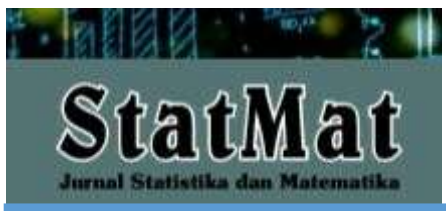

Tabel 5 Nilai Indeks RMSSTD Analisis Kelompok dengan 5 Metode

\begin{tabular}{crrrrr}
\hline $\begin{array}{c}\text { Jumlah } \\
\text { Kelompok }\end{array}$ & $\begin{array}{c}\text { Single } \\
\text { Linkage }\end{array}$ & $\begin{array}{c}\text { Median } \\
\text { Linkage }\end{array}$ & $\begin{array}{c}\text { Complete } \\
\text { Linkage }\end{array}$ & Ward's & $\begin{array}{c}\text { Centroid } \\
\text { Linkage }\end{array}$ \\
\hline 1 & 7,824 & 7,824 & 7,824 & 3,912 & 7,824 \\
2 & 7,937 & 8,050 & 8,050 & 8,050 & 8,050 \\
3 & 13,700 & 7,761 & 10,950 & 8,542 & 7,761 \\
4 & 19,501 & 9,358 & 11,527 & 10,478 & 9,358 \\
\hline
\end{tabular}

Berdasarkan Tabel 5, diperoleh hasil bahwa dengan menggunakan 5 metode pengelompokan pada analisis cluster hierarki, maka diperoleh kelompok optimum dengan nilai indeks RMSSTD terkecil terdapat pada metode Ward's dengan jumlah kelompok sebanyak 4 dan nilai RMSSTD yaitu 3,912.

Pengelompokan Kabupaten/Kota dengan menggunakan metode ward's dapat dilihat pada Tabel 6 .

Tabel 6 Pengelompokan Kabupaten/Kota

\begin{tabular}{lccc}
\hline \multicolumn{1}{c}{ Case } & 4 Clusters & 3 Clusters & 2 Clusters \\
\hline 1:Kepualauan Tanimbar & 1 & 1 & 1 \\
2:Maluku Tenggara & 2 & 1 & 1 \\
3:Maluku Tengah & 3 & 2 & 2 \\
4:Buru & 2 & 1 & 1 \\
5:Kepulaua Aru & 2 & 1 & 1 \\
6:Seram Bagian Barat & 2 & 1 & 1 \\
7:Seram Bagian Timur & 1 & 1 & 1 \\
8:Maluku Barat Daya & 1 & 1 & 1 \\
9:Buru Selatan & 1 & 1 & 1 \\
10:Ambon & 4 & 3 & 2 \\
11:Tual & 2 & 1 & 1 \\
\hline
\end{tabular}

Berdasarkan Tabel 6, dapat dilihat bahwa proses pengklasteran Kabupaten/Kota di Provinsi Maluku berdasarkan indikator IPM yaitu sebagai berikut.

1. Apabila dibentuk dalam 4 klaster, maka anggota klaster 1 meliputi Kabupaten Kepulauan Tanimbar, Seram Bagian Timur, Maluku Barat Daya dan Kabupaten Buru Selatan. Untuk anggota klaster 2 meliputi Kabupaten Maluku Tenggara, Buru, Kepulauan Aru, Seram Bagian Barat dan Kota Tual. untuk anggota klaster 3 yaitu Kabupaten Maluku Tengah dan untuk anggota klaster 4 yaitu Kota Ambon.

2. Apabila dibentuk dalam 3 klaster, maka anggota klaster 1 meliputi Kabupaten Kepulauan Tanimbar, Maluku Tenggara, Buru, Kepulauan Aru, Seram Bagian Barat, Seram Bagian Timur, Maluku Barat Daya, Buru Selatan, dan Kota Tual. Untuk anggota klaster 2 yaitu Kabupaten Maluku Tengah dan untuk anggota klaster 3 yaitu Kota Ambon.

3. Apabila dibentuk dalam 2 klaster, maka anggota klaster 1 meliputi Kabupaten Kepulauan Tanimbar, Maluku Tenggara, Buru, Kepulauan Aru, Seram Bagian 
Barat, Seram Bagian Timur, Maluku Barat Daya, Buru Selatan, Kota Tual dan Kabupaten Maluku Tengah dan untuk anggota klaster 2 yaitu Kota Ambon. Selanjunya untuk pengelompokan Kabupaten/Kota menggunakan dendogram dapat dilihat pada Gambar 2.

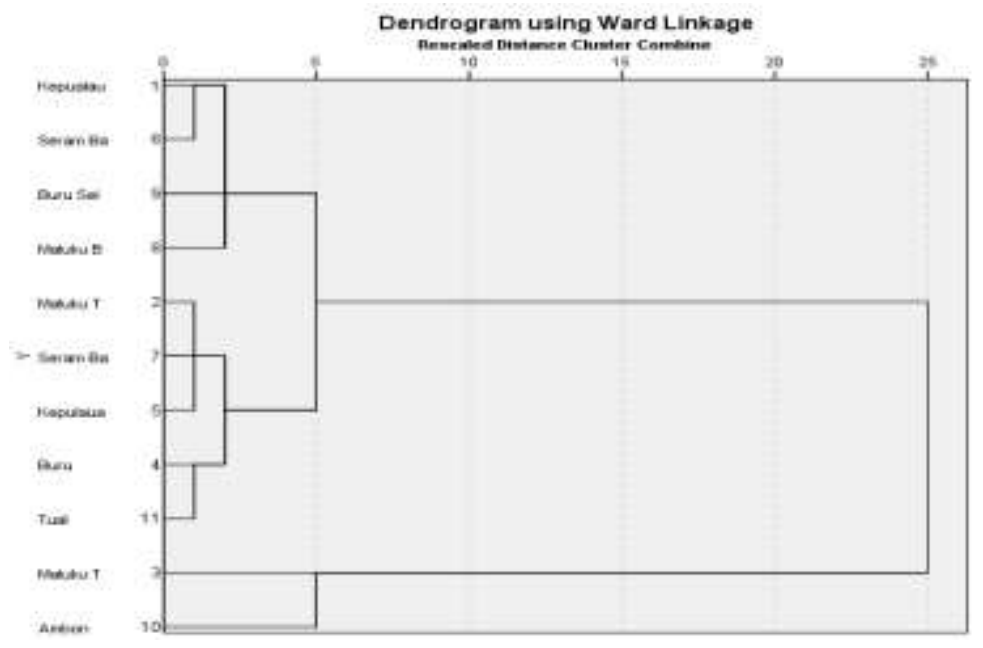

\section{Gambar 2 Dendogram Analisis Kelompik dengan Menggunakan Metdoe Ward's}

\section{KESIMPULAN}

Berdasarkan hasil dan pembahasan maka dapat disimpulkan sebagai berikut.

1. Penerapan analisis cluster dengen metode hierarki untuk klasifikasi Kabupaten/Kota di Provinsi Maluku berdasarkan indikator indeks pembangunan manusia (IPM) dilakukan dengan lima metode yaitu Single Linkage, Average Linkage, Complete Linkage, Ward's, dan Centroid. Diperoleh metode terbaik yaitu metode ward's. dengan jumlah sebanyak 4 cluster yang terdiri dari cluster dengan IPM tinggi yaitu cluster 4, cluster dengan IPM sedang yaitu pada cluster 3, cluster dengan IPM rendah yaitu pada cluster 2 dan selanjutnya cluster dengan IPM sangat rendah yaitu cluster 1 .

2. Analsis Cluster dengan metode hierarki pada Kabupaten/Kota di Provinsi Maluku berdasarkan indikator IPM yaitu sebagai berikut.

a. Apabila dibentuk dalam 4 klaster, maka anggota klaster 1 meliputi Kabupaten Kepulauan Tanimbar, Seram Bagian Timur, Maluku Barat Daya dan Kabupaten Buru Selatan. Untuk anggota klaster 2 meliputi Kabupaten Maluku Tenggara, Buru, Kepulauan Aru, Seram Bagian Barat dan Kota Tual. untuk anggota klaster 3 yaitu Kabupaten Maluku Tengah dan untuk anggota klaster 4 yaitu Kota Ambon.

b. Apabila dibentuk dalam 3 klaster, maka anggota klaster 1 meliputi Kabupaten Kepulauan Tanimbar, Maluku Tenggara, Buru, Kepulauan Aru, Seram Bagian Barat, Seram Bagian Timur, Maluku Barat Daya, Buru Selatan, dan Kota Tual. Untuk anggota klaster 2 yaitu Kabupaten Maluku Tengah dan untuk anggota klaster 3 yaitu Kota Ambon.

c. Apabila dibentuk dalam 2 klaster, maka anggota klaster 1 meliputi Kabupaten Kepulauan Tanimbar, Maluku Tenggara, Buru, Kepulauan Aru, Seram Bagian Barat, Seram Bagian Timur, Maluku Barat Daya, Buru Selatan, Kota Tual dan Kabupaten Maluku Tengah dan untuk anggota klaster 2 yaitu Kota Ambon. 


\section{DAFTAR PUSTAKA}

BPS Maluku. 2019. Maluku Dalam Angka Tahun 2018, Ambon.

Fathia, A. N., \& Rahmawati, R. 2016. Analisis Klaster Kecamatan Di Kabupaten Semarang Berdasarkan Potensi Desa Menggunakan Metode Ward Dan Single Linkage. None, 5(4), 801-810.

Lina, R., \& Eni, L. T. 2011. Analisis Kelompok Dengan Menggunakan Metode Hierarki Untuk Pengelompokan Kabupaten/Kota Di Jawa Timur Berdasar Indikator Kesehatan.

Matdoan, M. Y., Balami, A. M., \& Talakua, M. W. 2019. Pemodelan Regresi Nonparametrik Spline Truncated Pada Faktor-Faktor Yang Mempengaruhi Pertumbuhan Ekonomi Di Provinsi Maluku. VARIANCE : Journal of Statistics and Its Applications, 1(1), 27-37. https://doi.org/10.30598/variancevol1iss1page27-37.

Tambunan T.H Tulus. 2003. Perekonomian Indonesia. Ghalia Indonesia: Jakarta

Tangga, R., Jember, K., \& Data, A. M. P. 2013. dalam Mengidentifikasi Tipe Kawasan Berdasarkan Karakteristik Timbulan Sampah Rumah Tangga di Perkotaan Kabupaten Jember. 2(1), 1-5.

Rita Herawaty Br Bangun. 2016. Analisis Klaster Non Heirarki Dalam Pengelompokan Kabupaten/Kota di Sumatera Utara Berdasarkan Faktor Produksi Padi. Jurnal Agribisnis Sumatera Utara, 4(1), 54-61. 